\title{
ARBORIZAÇÃO URBANA: USO DE ESPÉCIES ARBÓREAS NATIVAS NA CAPTURA DO CARBONO ATMOSFÉRICO
}

\author{
Clenara Citron Muneroli ${ }^{1}$, Juan José Mascaró ${ }^{2}$ \\ (recebido em 17.09.2009 e aceito para publicação em 23.03.2010)

\section{RESUMO}

Este estudo teve como objetivo analisar a arborização urbana em dois trechos denominados de A e B na cidade de Carazinho RS. Os trechos localizam-se em dois bairros um exclusivamente residencial de baixa ocupação do solo urbano e outro residencial e comercial de densidade maior. Foi realizado um levantamento da vegetação existente nos logradouros dos bairros e aplicação de um breve questionário para obter informações sobre a percepção dos entrevistados quanto a arborização urbana local. Através do diagnóstico obtido nos dois trechos de estudo foi proposta uma nova alternativa de arborização, usando espécies arbóreas nativas da região que apresentam crescimento moderado e rápido para testar a melhoria da ambiência urbana e o aumentando na captura do carbono atmosférico. Observou-se que a falta de árvores nas vias de pedestre em vários pontos do trecho $\mathrm{A}$ se devem ao fato de serem estreitas tendo em média de $1 \mathrm{~m}$ a 1,50 m, causando desconforto em dias quentes. A relevância deste tema não é apenas com aspecto urbanístico e climático, mas também na captura do gás carbônico.

Palavras-chave: Arborização urbana. Espécies arbóreas nativas. Carbono.

\footnotetext{
1 Mestranda em Engenharia Infraestrutura e Meio Ambiente, Universidade de Passo Fundo. cmuneroli@hotmail.com

2 Arquiteto. juan@upf.br 


\title{
URBAN AFFORESTATION: USE OF NATIVE TREE SPECIES IN ATMOSPHERIC CARBON CAPTURE
}

\begin{abstract}
This study aimed to analyze the urban tree planting in two sections called A and B in the city of Carazinho RS. The portions are located in two residential districts one with low occupation of urban land and other residential and commercial with greater density. A survey of existing vegetation in public parks, neighborhoods and application of a brief questionnaire to obtain information on the perceptions of urban tree planting on the site. Through the diagnosis from the two portions of the study proposed a new alternative for afforestation using native species from the region who have moderate growth and rapid test for the improvement of urban ambience and increasing the capture of atmospheric carbon. It was observed that the lack of trees on the pedestrian routes in various parts of the section are due to the fact that they are narrow with an average of $1 \mathrm{~m}$ to $1.50 \mathrm{~m}$, causing discomfort on hot days. The relevance of this issue is not only urban aspect and climate, but also in the capture of carbon dioxide.
\end{abstract}

Key-words: Urban trees. Native arboreous species. Carbon.

\section{INTRODUÇÃO}

Nos últimos anos o homem trocou o ambiente rural para viver nas áreas urbanas, isso provocou um crescimento desordenado das cidades. Em Carazinho à situação não é diferente das demais cidades brasileiras. De acordo com os dados do censo IBGE, 2007 a população rural em 1970 era de 13.008 habitantes, a urbana de 29.544 habitantes e hoje a rural é de aproximadamente 3.000 habitantes e a urbana de 58.197 habitantes. Esta ocupação desordenada foi provocando mudanças no ambiente urbano principalmente nas áreas verdes, que aos poucos foram sendo substituídas por espaços edificados e pavimentados.

Segundo Mascaró (2004), quando se substitui as plantas por asfalto, tijolos e concreto, favorecem-se a absorção de radiação solar diurna e a reflexão noturna, formando assim o fenômeno das "ilhas de calor". A construção de edificações e indústrias em áreas urbanas cresce ocupando o lugar da arborização, que não é replantada, gerando um desconforto na ambiência urbana. 
Essa transformação na paisagem, em um cenário urbano, modifica os elementos naturais, como solo, temperatura, umidade, nebulosidade, mecanismos do vento, pluviosidade, flora e fauna. Esses elementos naturais são responsáveis, no geral, pelas condições de conforto ambiental (LOMBARDO, 1990; SANTOS e TEIXEIRA, 2001).

A arborização urbana proporciona vários benefícios ao ambiente entre eles pode-se, destacar a captura do carbono atmosférico, uma vez que a vegetação representa papel importante na absorção desse gás através do fenômeno da fotossíntese. Existem muitos projetos financiados por empresas para reflorestamento de áreas degradadas como forma de aumentar a capturar do carbono, porém há pouco estudo e incentivo financeiro, principalmente no Brasil, em áreas com florestas urbanas.

De forma específica, é importante estabelecer critérios para arborizar o ambiente urbano utilizando espécies arbóreas nativas com características próprias de cada região, pois o ambiente urbano, quando bem arborizado além da captura do carbono também aumenta a umidade do ar, controla a temperatura, fornece alimento à fauna silvestre, diminui a intensidade do vento e alivia o estresse da população.

Lorusso (1992) define arborização urbana como o conjunto de áreas verdes, compostas por três setores individualizados que estabelecem interfaces entre si: 1) áreas verdes públicas, destinadas ao lazer ou que oportunizam ocasiões de encontro e convívio direto com a natureza como praças e parques; 2) áreas verdes privadas, compostas pelos remanescentes vegetais significativos incorporados à malha urbana; e, 3) arborização de ruas e vias públicas.

A Sociedade Internacional de Arborização emprega o termo "urban forestry" florestas urbanas - que representa todo o conjunto de vegetação arbórea presente nas cidades, independente de sua localização (COSTA, 1997).

Segundo Paiva (2000), para implantar a arborização é importante escolher as espécies e avaliar alguns critérios, como o ritmo e as exigências para o crescimento, o tipo de copa, o porte, a folhagem, as flores, os frutos, os troncos, as raízes, os problemas de toxidez, a rusticidade, a resistência, a desrama natural e a origem das espécies; além de considerar outros fatores relevantes, entre eles, a largura da calçada, a rede de infraestrutura, o clima, o solo e a umidade.

Roberto Burle Marx contribuiu de forma determinante na introdução de espécies nativas junto às estruturas urbanas, valorizando a paisagem construída, inclusive, pela presença de árvores ornamentais, procurando utilizar espécies que eram ignoradas por paisagistas, o que permitiu que algumas fossem salvas de extinção (STRINGHETA, 2005). 
A escolha da espécie adequada para ser utilizada em um determinado local é fundamental quando se planeja a arborização urbana. Uma escolha bem feita irá diminuir os custos de manutenção que ocorrem quando colocadas em local errado, sem o mínimo planejamento. Durante a fase de planejamento da arborização urbana, vários critérios devem ser adotados: em canteiros centrais de avenidas e em ruas de calçadas largas, pode-se optar por espécies de porte grande e médio, porém em calçadas estreitas, devemse usar espécies de pequeno porte para não causar interferências principalmente com a rede de infraestrutura (PAIVA, 2000).

Nas cidades, onde já está implantada a arborização urbana é necessário, um acompanhamento técnico, uma reformulação do planejado junto com participação da comunidade, onde serão observados os seguintes condicionantes: estudo da espécie, comportamento no meio urbano, integralização com os outros elementos da cidade, dimensões de ruas e passeios, altura das construções, presença de redes aéreas ou subterrâneas, localização das diferentes atividades, condições de clima e solo, fluxo de veículos e pedestres (CUNHA, 2005).

As árvores urbanas diminuem o nível de carbono atmosférico quatro vezes mais do que as árvores individuais não urbanas, porque a diferença está relacionada com a variação no tamanho do diâmetro das copas (NOWAK e CRANE, 2002). Mc Pherson (1994) num estudo realizado com 118 árvores na cidade de Chicago constatou uma média de crescimento anual do DAP de 1,1 centímetros, em comparação com 0,4 centímetros em árvores plantadas em áreas florestais em Indiana e Illinois/Chicago, USA.

$O$ atual crescimento da concentração de carbono na atmosfera, deriva da injeção de cerca de 8 a 9 bilhões de toneladas de carbono por ano (na forma de $\mathrm{CO}_{2}$ ), que ocorre pelo alto consumo de combustíveis fosseis e pela queimada e desmatamento das florestas. $E$ esses fenômenos, injetam um total de aproximadamente 3,2 bilhões de toneladas que permanecem na atmosfera, o restante é absorvido pelos oceanos e pelas plantas (NOBRE 2004).

Segundo Floss (2006) o desenvolvimento da planta acontece na presença de luz, através da síntese da clorofila, permitindo, assim, que inicie o processo fisiológico mais importante na vida das plantas, a fotossíntese. A partir deste momento, a planta torna-se independente (autotrófica), pois passa a produzir o seu próprio material orgânico, com ajuda das substâncias inorgânicas (água e gás carbônico), utilizando como fonte de energia a luz solar. Assim é que as plantas realizam a captura do carbono da atmosfera e contribuem significativamente de forma a diminuir os efeitos deste gás no aquecimento global. 
Este estudo de caso teve como objetivo estabelecer critérios para o planejamento da arborização urbana na cidade de Carazinho RS, visando amenizar os efeitos dos poluentes atmosféricos, priorizando o uso de espécies arbóreas nativas do Rio Grande do Sul de forma a contribuir com a captura do carbono atmosférico.

\section{MATERIAIS E MÉTODOS}

O estudo de caso ocorreu na cidade de Carazinho no Rio Grande do Sul, distante 295 km da capital Porto Alegre, com coordenadas geográficas globais 28'15'15" (latitude Sul) e 52'42'20" (longitude Oeste) figura 1. A população total do município de Carazinho, conforme estimativa do IBGE em 2007 é de 58.197 habitantes, distribuídos numa área territorial total de $665 \mathrm{~km}^{2}$, sendo que $114,75 \mathrm{~km}^{2}$ compreendem o perímetro urbano e $550,25 \mathrm{~km}^{2}$ as áreas rurais.

A densidade populacional na área urbana é de pouco mais de 508 habitantes $/ \mathrm{km}^{2}$, e a rural de aproximadamente 6,50 habitantes $/ \mathrm{km}^{2}$. O clima local é descrito como subtropical úmido, com chuva bem distribuída durante o ano e temperatura média do mês mais quente superior a $22^{\circ} \mathrm{C}$.

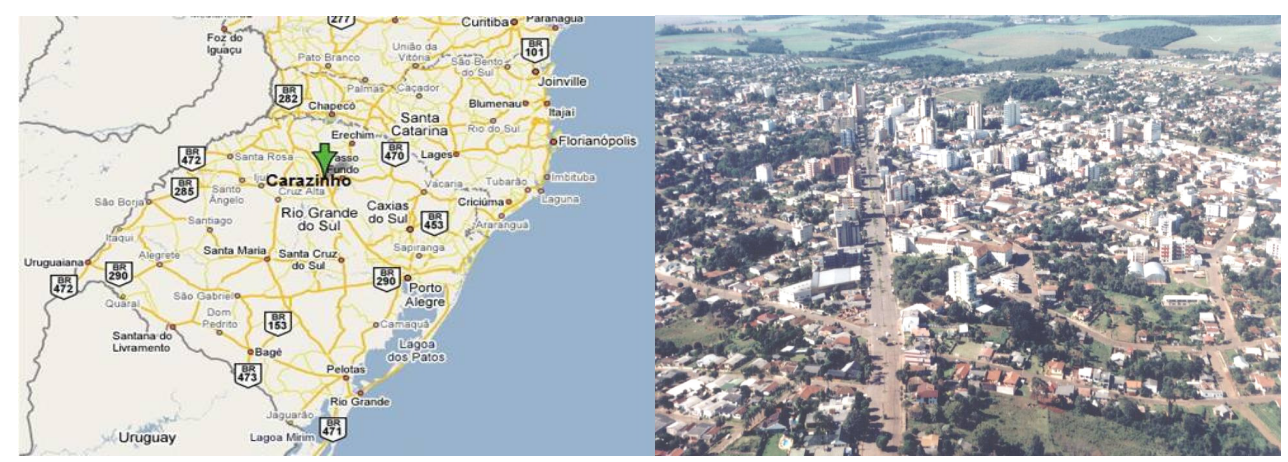

Figura 1: Mapa da localização do Município de Carazinho e foto aérea da cidade.

Fonte: Google Maps, 2008.

O trabalho foi desenvolvido em duas áreas da cidade de Carazinho, RS, que são denominadas de trecho A e B. Foram realizadas observações, relato fotográfico e inventário da arborização urbana existente nos logradouros, bem como a coleta de informações, através da aplicação de questionários com os usuários, com o objetivo de esboçar as bases para um planejamento para a arborização urbana que seja apropriada para as duas áreas de estudo.

As seleções das duas áreas ocorreram através de alguns critérios, apresentados na Tabela 1 que foram fatores determinantes para a escolha dos dois trechos de estudo.

Tabela 1: Critérios de seleção para a escolha dos trechos A e B 


\begin{tabular}{l|l}
\hline \multicolumn{1}{c|}{ Trecho A } & \multicolumn{1}{c}{ Trecho B } \\
\hline Alta densidade de ocupação do solo & Baixa densidade de ocupação do solo \\
Caixa de rua larga & Caixa de rua estreita \\
Maior fluxo de pessoas e automóveis & $\begin{array}{l}\text { Menor fluxo de pessoas e automóveis } \\
\text { Vegetação adulta que causa interferências na rede de } \\
\text { Vegetação nova que não causa interferência na rede } \\
\text { infraestrutura aérea }\end{array}$ \\
Menor interferência de vento pela edificação elevada & $\begin{array}{l}\text { Maior interferência do vento pela baixa edificação } \\
\text { Maior pavimentação do solo (asfalto) }\end{array}$ \\
Menor infiltração de água no solo & $\begin{array}{l}\text { Menos pavimentação (pedra basalto) } \\
\text { Zona residencial e comercial }\end{array}$ \\
\hline
\end{tabular}

O inventário da vegetação permitiu caracterizar as espécies arbóreas existentes e assim estabelecer um diagnóstico atual da arborização, para a elaboração de propostas novas a serem empregadas em ambos os trechos de estudo. Para a realização do inventário foi elaborada uma planilha com anotações dos dados das árvores, tais como; altura geral, diâmetro da copa, DAP - Diâmetro na Altura do Peito, local de plantio, estado fitossanitário e interferência com a rede de infraestrutura.

Também foram aplicados 50 questionários, 40 no trecho $A$, pois o número de pessoas que habitam e circulam no local é quatro vezes maior que no trecho $B$, onde foram aplicados 10 questionários.

Os questionários serviram para avaliar o grau de satisfação dos usuários sobre a arborização urbana em cada trecho e da cidade como um todo. A aplicação ocorreu através de entrevista face a face com livre escolha nas respostas. Garantindo o anonimato dos respondentes, as perguntas não têm uma seqüência lógica, onde o roteiro estipulado seguiu os objetivos da pesquisa.

\section{RESULTADOS E DISCUSSÃO}

\subsection{Aplicação do questionário}

\subsubsection{Avaliação da arborização pelos moradores}

Os dados obtidos foram processados e tabulados a fim de gerar gráficos, que permitam analisar as informações, tornando possível identificar a opinião dos usuários. $\mathrm{O}$ modelo de questionário foi elaborado com base em APO, Avaliação Pós-Ocupação (ORNSTEIN, 1992).

Os resultados dos questionários revelaram que a maioria dos entrevistados, nos dois trechos de estudo, sabem o quanto são importantes ambientes arborizados para a melhoria 
da ambiência urbana, mas não estão satisfeitos com a atual arborização de Carazinho, apontando como causa a falta de árvores na via de pedestres, canteiro central e praças. Outro fator apontado foi referente aos problemas gerados por interferência das árvores na rede de infraestrutura, que ocorrem pela falta de planejamento na arborização urbana.

No que se refere às vantagens proporcionadas por um ambiente bem arborizado, os entrevistados conhecem os benefícios que a arborização proporciona ao ambiente da cidade ajudando a amenizar as altas temperaturas no verão. Os gráficos da Figura 2 mostram os resultados dos questionários em cada uma das perguntas realizadas aos usuários nos dois trechos de estudo. 
Trecho A
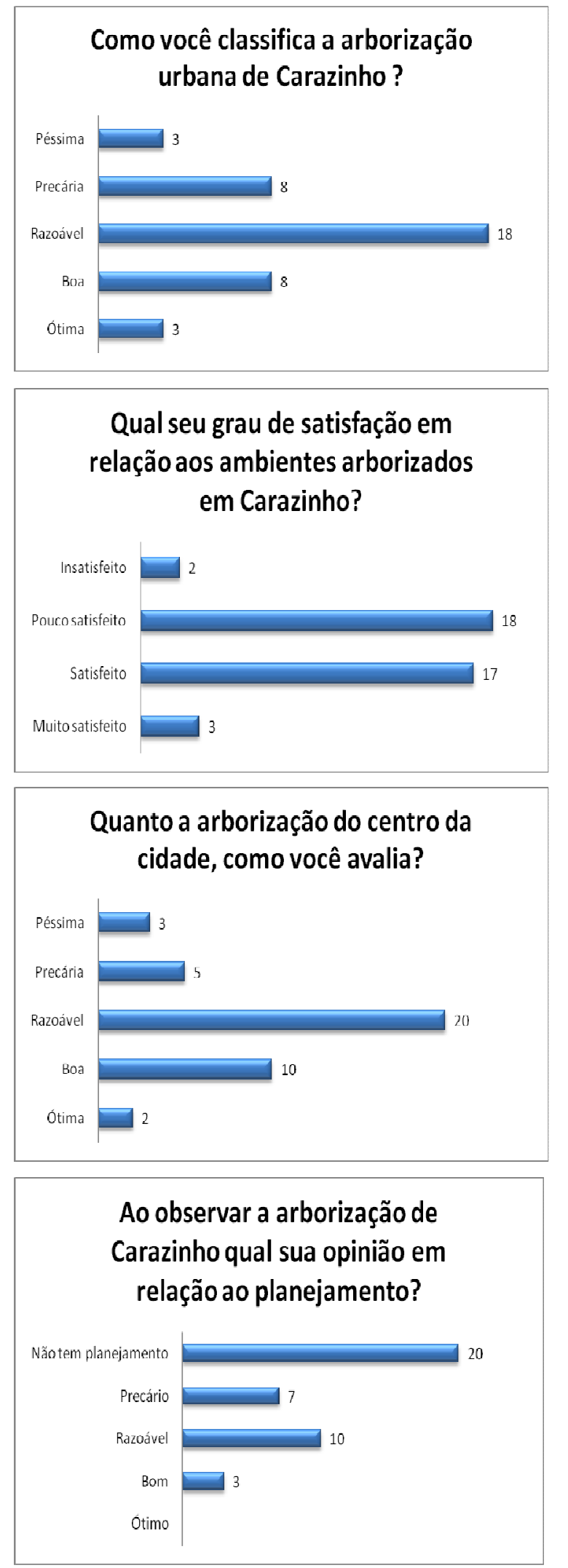

Trecho B
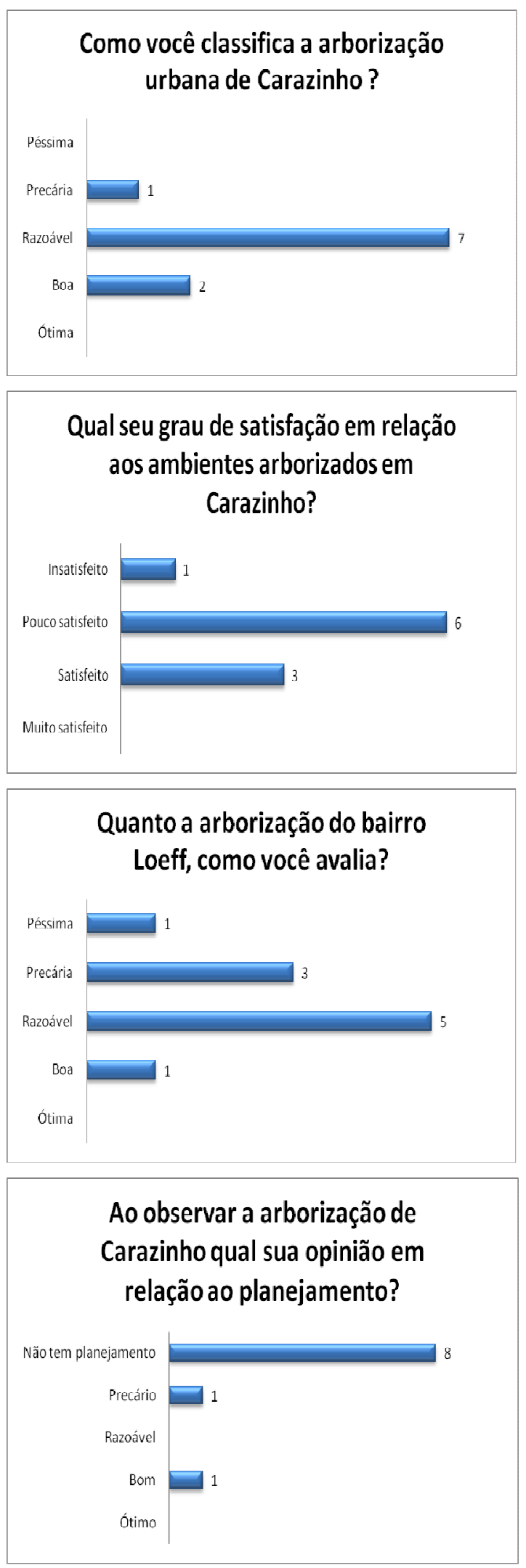

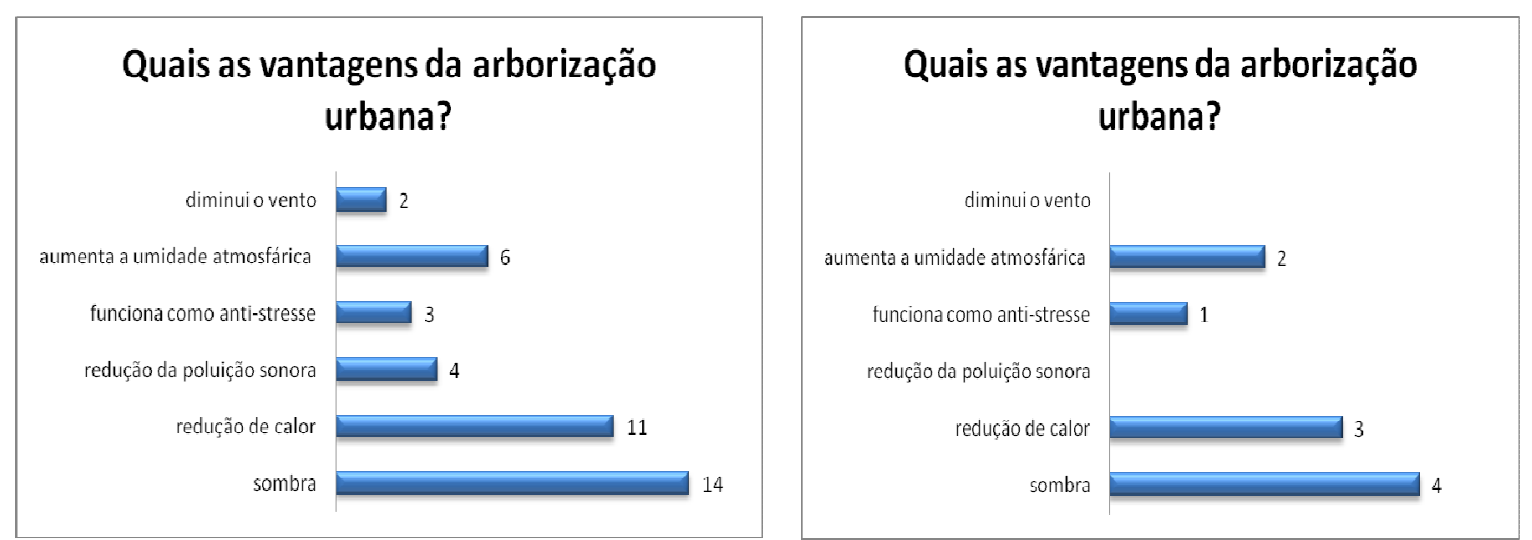

Figura 2: Gráficos com a opinião dos usuários nos trechos A e B respectivamente.

\subsection{Inventário da arborização}

Os levantamentos da arborização nos dois trechos de estudo permitiram conhecer as espécies arbóreas existentes nestes locais bem como a qualidade e quantidade das espécies. O inventário da vegetação é um meio importante para verificar os erros e acertos na arborização de uma cidade.

No trecho $A$, as espécies existentes são, na maioria nativa de tipos variados, desempenhando um papel importante para o ambiente, pois as características são propícias para seu desenvolvimento. O que ocorre neste trecho é a interferência das árvores com a rede de infraestrutura aérea, devido às árvores serem de grande porte. A extensão estudada no trecho $A$ foi $1.534 \mathrm{~m}$ com 60 árvores inventariadas, sendo 46 nativas e 14 exóticas.

Vários locais do trecho A não são preenchidos com árvores, principalmente, as vias de pedestres. Esses espaços poderiam ser mais aproveitados com a introdução de novas espécies, visando melhorar o aspecto urbanístico e a ambiência urbana. O trecho apresenta problemas no que se refere à via de pedestre que apresenta em média um metro e meio de largura, impedindo o plantio de árvores uma vez que atrapalharia a circulação dos pedestres.

No trecho B a extensão de estudo inventariada foi de aproximadamente $1.473 \mathrm{~m}$ que apresentou 109 árvores. Destas 60 pertencem as espécies nativas e 49 a exóticas. Nesse trecho ocorre um equilíbrio quanto à presença de espécies nativas e exóticas, não existe muita interferência das árvores na a rede de infraestrutura aérea, pois apresentam porte adequado para o local, mas pode-se observar a pouca variabilidade de espécies, predomínando canela (Nectandra sp), jerivá (Syagrus romanzoffiana) e cipreste (Cupressus sempervirens).

Nesse trecho, algumas vias de pedestres não estão arborizadas, causando desconforto em dias muito quentes. Percebe-se que a maior parte da arborização foi 
introduzida pelos moradores, que se preocuparam mais com o aspecto de embelezamento do bairro.

Possuem vias de pedestres com largura de $2 \mathrm{~m}$ e $3 \mathrm{~m}$, sem padrão na execução, pois em determinados pontos é revestida de grama ou grama/ pavimento e outros apenas pavimento. Os locais que apresentam somente grama dificultam o trajeto dos pedestres em dia de chuva, quando o solo fica encharcado de água.

\subsection{Proposta de arborização para aplicar no trecho A e trecho B}

Com base nos dados obtidos das espécies arbóreas presentes nos dois trechos de estudo e a opinião dos usuários sobre a arborização urbana, foi selecionada uma quadra do trecho A e uma quadra do trecho B para propor um projeto que possa melhorar o conforto da população e aumentar a capturar do carbono da atmosfera.

É importante a observação de alguns critérios no momento em que novas espécies arbóreas serão introduzidas no passeio público nos dois trechos da cidade:

- Caracterizar o bairro se é de alta ou baixa densidade de ocupação do solo urbano, tipo de edificação e fluxo de pessoas e automóveis;

- Permitir a participação dos usuários na elaboração do projeto de arborização;

- Deixar as espécies que já estão no local e que não apresentam injúrias;

- Manejar as espécies que estão causando interferências nas redes de infraestrutura ou optar por novas redes adaptadas a cada situação;

- Introduzir novas espécies;

- Dar preferência às espécies nativas previamente selecionadas;

- Observar se a espécies é decídua, proporcionando espaços sombreados no verão e passagem de radiação solar no inverno;

- Em área comercial, observar o fuste da árvore para permitir a visibilidade das vitrines das lojas;

- Cuidar para que a espécie escolhida não interfira nas redes de infraestrutura, sejam elas aéreas ou subterrâneas;

- Levar em conta o aspecto paisagístico do bairro;

- Padronizar a pavimentação do passeio público, observando as normas para áreas residenciais e comerciais.

- Existem várias formas para realizar o cálculo de absorção de carbono em árvores, o método usado nesse trabalho de pesquisa foi obtido a partir das investigações realizadas pelo pesquisador David Nowak em árvores urbanas. O guia elaborado por Nowak não é a única 
forma de calcular a quantidade de carbono absorvido, mas é um guia simples que pode ser aplicado em vários locais.

- É necessário algumas informações sobre a espécie arbórea a ser utilizada; nome comum, idade, desenvolvimento (lento, moderado ou rápido), se a árvore é do tipo folhosa ou conífera e se seu porte é pequeno, médio ou grande.

A Tabela 2 apresenta os itens que deverão ser observados para realizar o cálculo de captura do carbono. O item "A" determina as características da espécie, como o nome, tipo de árvore se é folhosa ou conífera e a taxa de crescimento. No item "B", deve-se indicar a idade da árvore. O item "C" quantas árvores são plantadas ou que existem num determinado local. O item "D" vai estabelecer o fator de sobrevivência da árvore (tabela em anexo). No item "E", para calcular o número de árvores que sobreviveram, tem que multiplicar o resultado do item C pelo item D. O item "F" demonstra a taxa anual que o carbono é capturado (tabela em anexo). O item "G" fornece o total de carbono capturado, multiplicando o item E pelo o item F.

Para ser compatível com normas nacionais e internacionais o peso atômico do Carbono deve ser multiplicado por 3,67 para transformar em peso molecular de $\mathrm{CO}_{2}$ e dividir por 1000 para transformar o valor obtido em toneladas.

Tabela 2: Modelo de planilha usada para cálculo de captura do carbono em árvores de áreas urbanas.

\begin{tabular}{|c|c|c|c|c|c|c|c|c|}
\hline \multicolumn{3}{|c|}{$\frac{\text { A }}{\text { Característica da espécie }}$} & \multirow{2}{*}{ 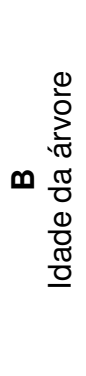 } & \multirow{2}{*}{ 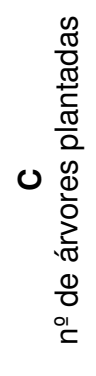 } & \multirow{2}{*}{ 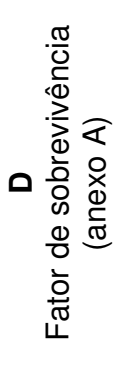 } & \multirow{2}{*}{ 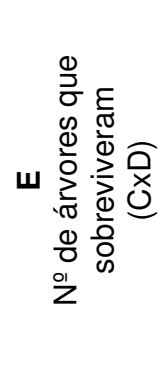 } & \multirow{2}{*}{ 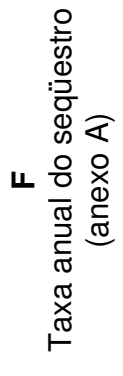 } & \multirow{2}{*}{ 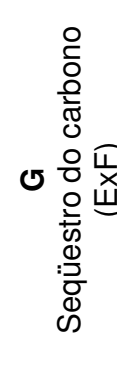 } \\
\hline Nome & 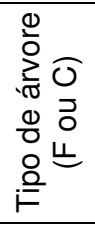 & 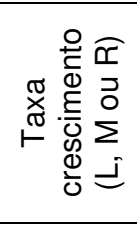 & & & & & & \\
\hline & & & & & & & & \\
\hline \multicolumn{8}{|c|}{ Total de seqüestro de carbono (1) } & \\
\hline \multicolumn{8}{|c|}{ Total de $\mathrm{Kg}$ equivalente ao seqüestro de $\mathrm{CO}_{2}=(1) \times 3.67(2)$} & \\
\hline \multicolumn{8}{|c|}{ Seqüestro de carbono equivalente em toneladas (2)/1000 } & \\
\hline
\end{tabular}

Proposta para o trecho A - com alta densidade de ocupação do solo, caixa de rua larga, grande fluxo de pessoas e automóveis e zona comercial e residencial.

A proposta no trecho A, foi desenvolvida em uma quadra da Avenida Flores da Cunha, observando-se a arborização atual e simulação do cálculo de absorção do carbono. A Figura 3 apresenta como se encontra a arborização nesse espaço, 8 árvores, sendo elas das espécies, fícus (Ficus benjamina), sibipiruna (Caesalpinia peltophoroides), cheflera (Schefflera arborícola) e aroeira vermelha ( Schinus terebinthifolius). 

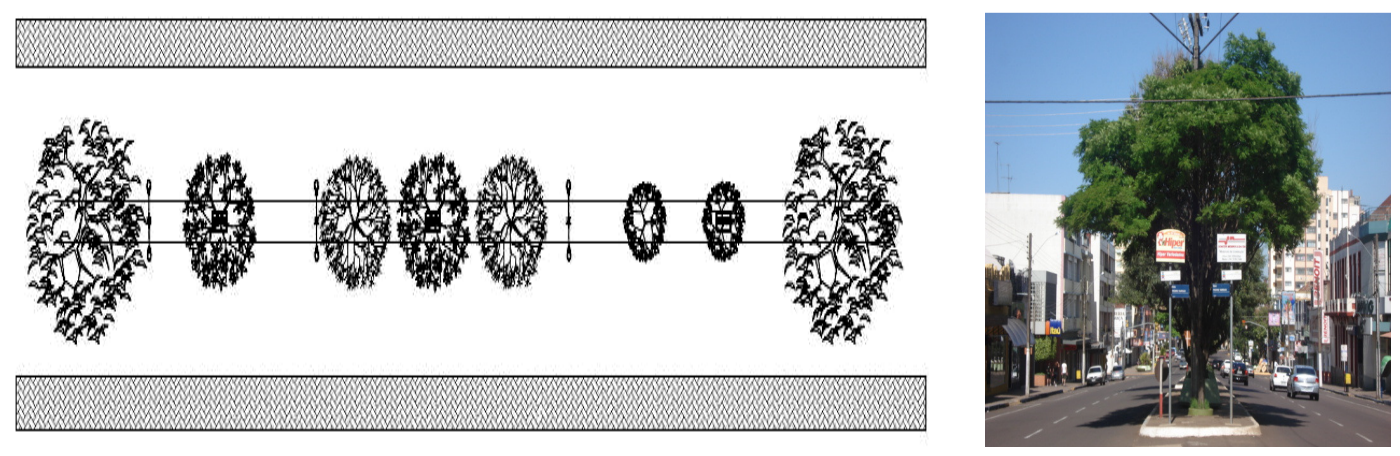

Figura 3: Croqui e fotografia da situação atual da arborização urbana no trecho da Avenida Flores da Cunha, Carazinho RS.

Para a simulação do cálculo de captura de carbono ( tabela 3) foi padronizada a idade das árvores uma vez que a grande maioria tem aproximadamente 20 anos de idade e aplicada ao modelo de planilha elaborada por Nowak (tabela em anexo).

Tabela 3: Cálculo de captura de carbono da situação existente no trecho A.

\begin{tabular}{|c|c|c|c|c|c|c|c|c|}
\hline \multicolumn{3}{|c|}{$\stackrel{\text { A }}{\text { Característica da espécie }}$} & \multirow{2}{*}{$\begin{array}{r}\frac{0}{0} \\
\infty \\
\infty \\
\frac{\pi}{0} \\
\frac{\pi}{0} \\
\frac{0}{0} \\
\frac{\pi}{0}\end{array}$} & \multirow{2}{*}{ 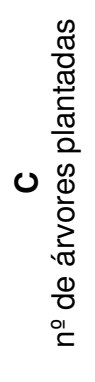 } & \multirow{2}{*}{ 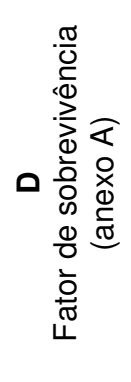 } & \multirow{2}{*}{ 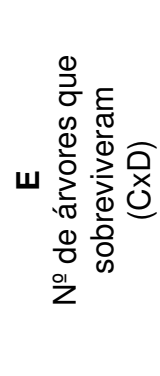 } & \multirow{2}{*}{ 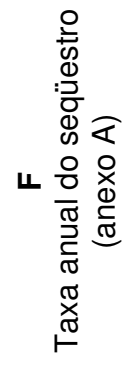 } & \multirow{2}{*}{ 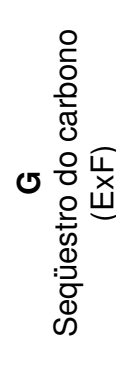 } \\
\hline Nome & 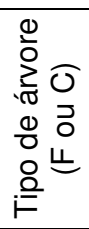 & 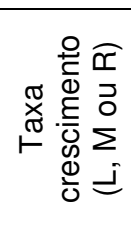 & & & & & & \\
\hline Sibipiruna & $\mathrm{F}$ & $\mathrm{M}$ & 20 & 2 & 0.462 & 0.924 & 23.2 & 21.4 \\
\hline Ficus & $\mathrm{F}$ & $\mathrm{L}$ & 20 & 2 & 0.448 & 0.896 & 10.8 & 9.6 \\
\hline Aroeira Vermelha & $\mathrm{F}$ & $\mathrm{M}$ & 20 & 2 & 0.462 & 0.924 & 23.2 & 21.4 \\
\hline Cheflera & $\mathrm{F}$ & $\mathrm{M}$ & 20 & 2 & 0.462 & 0.924 & 23.2 & 21.4 \\
\hline \multicolumn{8}{|c|}{ Total de seqüestro de carbono(1) } & 73.8 \\
\hline \multicolumn{8}{|c|}{ Total de kg equivalente ao seqüestro de $\mathrm{CO}_{2}(1) \times 3.67(2)$} & 270.8 \\
\hline \multicolumn{8}{|c|}{ Captura de carbono equivalente em toneladas (2) /1000 } & $0.2 \mathrm{t}$ \\
\hline
\end{tabular}

Para o mesmo local da avenida, elaborou-se uma nova proposta de arborização conforme mostra a figura 4, utilizando melhor os espaços que podem ser arborizados, proporcionando mais conforto aos pedestres. Permaneceram as espécies existentes e foram introduzidas outras, tais como ipê amarelo (Tabebuia alba), manacá da serra (Tibouchina mutabilis), chuva de ouro (Cássia ferruginea) e canela (Nectandra sp.). 


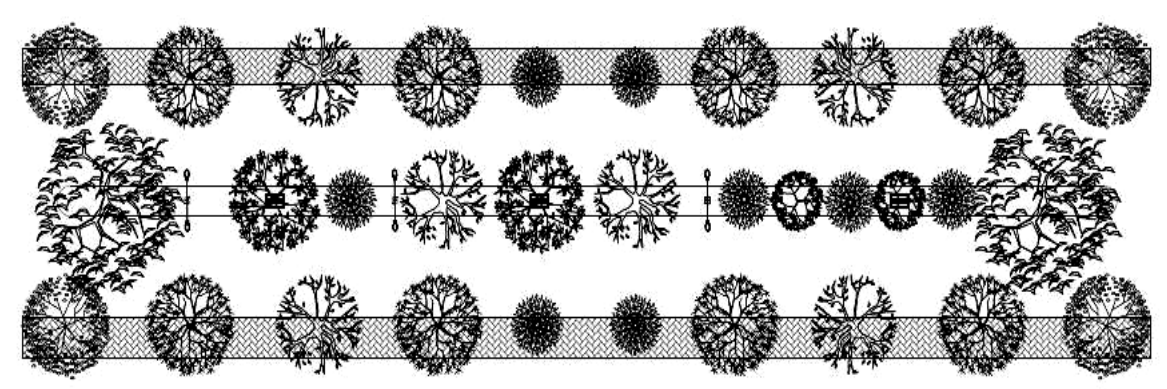

Figura 4: Croqui da distribuição de novas espécies arbóreas neste espaço do trecho A.

A Tabela 4 apresenta as anotações das características apresentadas pelas novas espécies arbóreas introduzidas nesse trecho de estudo.

Tabela 4. Cálculo simulando a captura do carbono na situação proposta para o trecho $A$.

\begin{tabular}{|c|c|c|c|c|c|c|c|c|}
\hline \multicolumn{3}{|c|}{$\begin{array}{c}\mathrm{A} \\
\text { Característica da espécie }\end{array}$} & \multirow{2}{*}{ 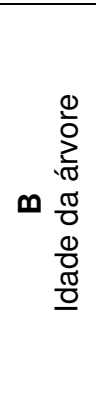 } & \multirow{2}{*}{ 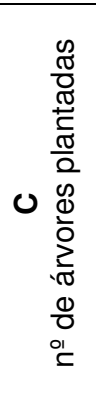 } & \multirow{2}{*}{ 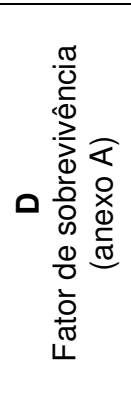 } & \multirow{2}{*}{ 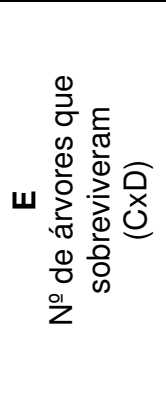 } & \multirow{2}{*}{ 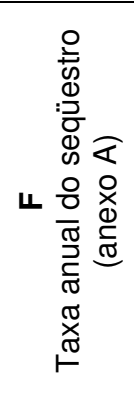 } & \multirow{2}{*}{ 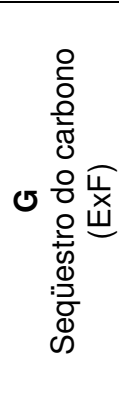 } \\
\hline Nome & 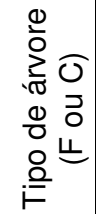 & 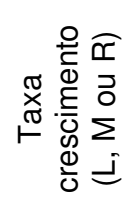 & & & & & & \\
\hline Chuva-de-ouro & $\mathrm{F}$ & $\mathrm{R}$ & 20 & 4 & 0.474 & 1.896 & 41.0 & 77.7 \\
\hline Ipê amarelo & $\mathrm{F}$ & $\mathrm{R}$ & 20 & 6 & 0.474 & 2.844 & 41.0 & 116.6 \\
\hline Manacá-da-serra & $\mathrm{F}$ & $\mathrm{M}$ & 20 & 8 & 0.462 & 3.696 & 23.2 & 85.7 \\
\hline Ficus & $\mathrm{F}$ & $\mathrm{L}$ & 20 & 2 & 0.448 & 0.896 & 10.8 & 9.6 \\
\hline Chiflera & $\mathrm{F}$ & $\mathrm{M}$ & 20 & 2 & 0.462 & 0.924 & 23.2 & 21.4 \\
\hline Sibipiruna & $\mathrm{F}$ & $\mathrm{M}$ & 20 & 2 & 0.462 & 0.924 & 23.2 & 21.4 \\
\hline Canela & $\mathrm{F}$ & $\mathrm{R}$ & 20 & 8 & 0.474 & 3.792 & 41.0 & 155.4 \\
\hline \multicolumn{8}{|c|}{ Total de seqüestro de carbono(1) } & 487.8 \\
\hline \multicolumn{8}{|c|}{ Total de kg equivalente ao seqüestro de $\mathrm{CO}_{2}(1) \times 3.67(2)$} & 1790.2 \\
\hline \multicolumn{8}{|c|}{ Seqüestro de carbono equivalente em toneladas (2)/1000 } & $1.7 t$ \\
\hline
\end{tabular}

A absorção de carbono aumentou consideravelmente passando de aproximadamente 0, 2 toneladas para 1,7 toneladas. Isso demonstra que a arborização, quando executada de forma planejada, procurando usar árvores de crescimento médio e rápido, pois aumentam a captura do carbono bem como beneficiam a ambiência urbana, oferecendo aos pedestres mais conforto em dias quentes, pois no trecho $A$ atualmente não tem arborização no passeio público.

a) Proposta para o trecho B - O Bairro Loeff, tem baixa densidade de ocupação do solo, caixa de rua estreita, exclusivamente residencial com pouco fluxo de pessoas e automóveis.

Para o estudo de caso, neste Bairro, foi usada uma quadra da Rua Marechal Deodoro; a Figura 5 apresenta a atual situação da arborização e a pavimentação do passeio público. Nessa quadra o passeio público em alguns pontos é revestido com pavimento, pavimento e Prop 
grama ou apenas grama. As espécies presentes são jerivá (Syagrus romanzoffiana) e canela (Nectandra sp.).
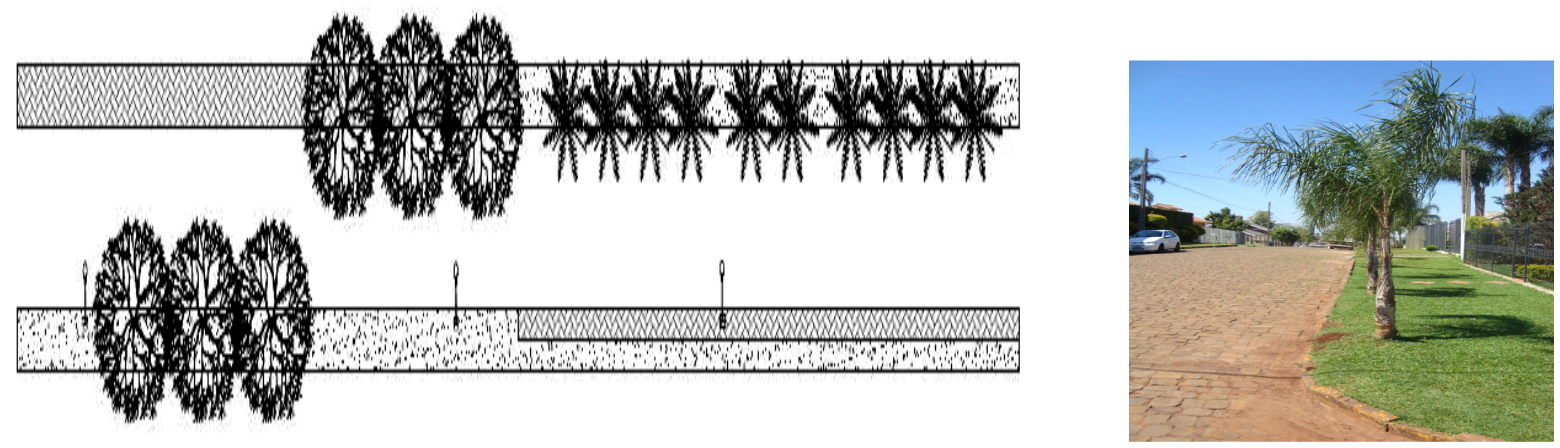

Figura 5: Croqui e fotografia do trecho na Rua Marechal Deodoro, no Bairro Loeff.

$\mathrm{Na}$ simulação da captura de carbono nesse trecho foi padronizada a idade das árvores seguindo as mesmas ações propostas na Tabela 3, porem neste trecho a maioria árvores tem aproximadamente 10 anos de idade, é o que apresenta a Tabela 5.

Tabela 5. Planilha com os dados das árvores e a captura de carbono na Rua Marechal Deodoro.

A

Característica da espécie

\begin{tabular}{|c|c|c|c|c|c|c|c|c|}
\hline \multicolumn{3}{|c|}{ Característica da espécie } & \multirow{2}{*}{ 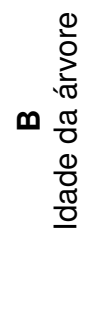 } & \multirow{2}{*}{ 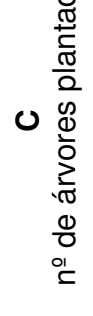 } & \multirow{2}{*}{ 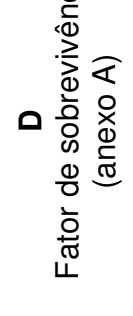 } & \multirow{2}{*}{ 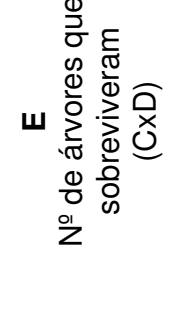 } & \multirow{2}{*}{ 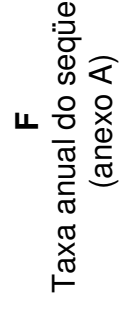 } & \multirow{2}{*}{ 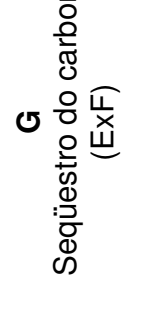 } \\
\hline Nome & 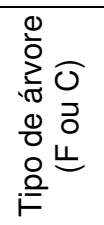 & 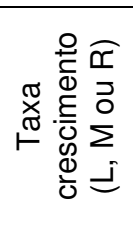 & & & & & & \\
\hline Jerivá & $\mathrm{F}$ & $\mathrm{M}$ & 10 & 10 & 0.576 & 5.76 & 11.2 & 64.5 \\
\hline Canela & $\mathrm{F}$ & $\mathrm{M}$ & 10 & 6 & 0.576 & 3.456 & 11.2 & 38.7 \\
\hline \multicolumn{8}{|c|}{ Total de seqüestro de carbono(1) } & 103.2 \\
\hline \multirow{2}{*}{\multicolumn{8}{|c|}{$\begin{array}{l}\text { Total de kg equivalente ao seqüestro de } \mathrm{CO}_{2}=(1) \times 3.67(2) \\
\text { Seqüestro de carbono equivalente em toneladas }(2) / 1000\end{array}$}} & 378.7 \\
\hline & & & & & & & & $0.3 \mathrm{t}$ \\
\hline
\end{tabular}

Para o mesmo local na Rua Marechal Deodoro, foi elaborado uma nova proposta de arborização, com outras espécies, deixando o local mais arborizado. Também foi padronizada a pavimentação do passeio público, seguindo as normas propostas pela prefeitura municipal de Carazinho. As espécies introduzidas foram, aroeira periquita (Schinus molle), ipê amarelo (Tabebuia alba), manacá da serra (Tibouchina mutabilis), e ipê roxo (Tabebuia avellanedae). 


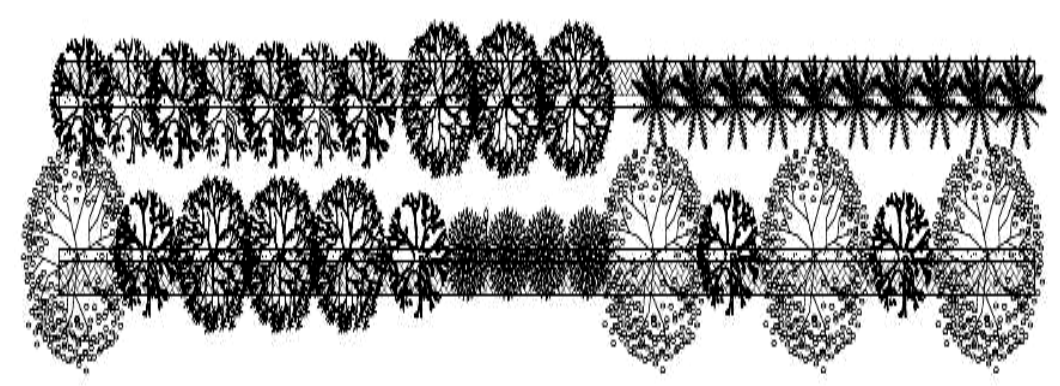

Figura 6. Croqui da nova disposição da arborização para o trecho da Rua Marechal Deodoro no Bairro Loeff.

A Tabela 6 apresenta os dados das espécies arbóreas propostas na simulação da captura de carbono.

Tabela 6. Planilha com o preenchimento dos dados das árvores e a captura do carbono para a nova proposta de arborização no trecho B.

A

Característica da espécie

\begin{tabular}{|c|c|c|c|c|c|c|c|c|}
\hline & \multirow{2}{*}{ 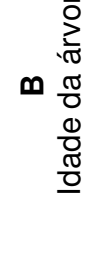 } & \multirow{2}{*}{ 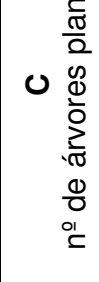 } & \multirow{2}{*}{ 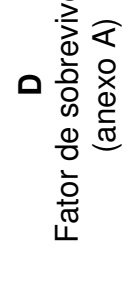 } & \multirow{2}{*}{ 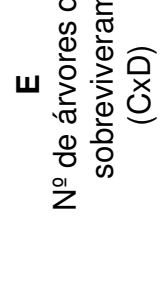 } & \multirow{2}{*}{ 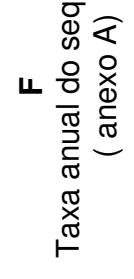 } & \multirow{2}{*}{ 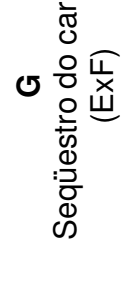 } \\
\hline Nome & 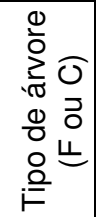 & 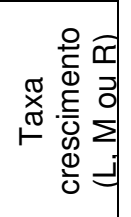 & & & & & & \\
\hline Ipê-amarelo & $\mathrm{F}$ & $\mathrm{R}$ & 10 & 8 & 0.589 & 4.712 & 19.3 & 90.9 \\
\hline Ipê-roxo & $\mathrm{F}$ & $\mathrm{M}$ & 10 & 3 & 0.576 & 1.728 & 11.2 & 19.3 \\
\hline Canela & $\mathrm{F}$ & $\mathrm{R}$ & 10 & 6 & 0.589 & 3.534 & 19.3 & 68.2 \\
\hline Aroeia-periquita & $\mathrm{F}$ & $\mathrm{R}$ & 10 & 5 & 0.589 & 2.945 & 19.3 & 56.8 \\
\hline Jerivá & $\mathrm{F}$ & $\mathrm{M}$ & 10 & 10 & 0.576 & 5.76 & 11.2 & 64.5 \\
\hline Manacá-da-serra & $\mathrm{F}$ & $\mathrm{M}$ & 10 & 4 & 0.576 & 2.304 & 11.2 & 25.8 \\
\hline \multicolumn{8}{|c|}{ Total de seqüestro de carbono(1) } & 325.5 \\
\hline \multicolumn{8}{|c|}{ Total de $\mathrm{kg}$ equivalente ao seqüestro de $\mathrm{CO}_{2}=(1) \times 3.67(2)$} & 1194.5 \\
\hline \multicolumn{8}{|c|}{ Seqüestro de carbono equivalente em toneladas (2) $/ 1000$} & $1.1 \mathrm{t}$ \\
\hline
\end{tabular}

Com o aumento no número de espécies arbóreas houve um aproveitamento dos espaços que não estavam arborizados, a absorção de carbono também teve um aumento significativo de 0,3 toneladas/ano passando para 1,1 toneladas/ano. Esse resultado demonstra que ainda há muito para ser feito na arborização urbana de Carazinho, pois existem vários espaços que não estão arborizados.

As políticas públicas deveriam cuidar mais da arborização urbana, pois, cada vez mais cresce seu importante papel para promover a ambiência urbana, a qualidade de vida da população e o aumento na captura do carbono atmosférico.

\subsection{Proposta de arborização em passeio público estreito}

Em vários locais na cidade de Carazinho, principalmente nas ruas transversais da Avenida Flores da Cunha, o passeio público é muito estreito com aproximadamente 1,5 
metro de largura, não havendo a possibilidade de implantação da arborização, para não dificultar a passagem dos pedestres, principalmente aos que apresentam algum tipo de deficiência física. Existem duas propostas para introduzir a arborização em via de pedestre estreita:

a) Diminuir a largura da caixa de rua e aumentar um lado do passeio público para o plantio de árvores (figura 7), utilizando neste mesmo lado estacionamento dos automóveis para fornecer sombra; esta proposta não prejudicaria o fluxo dos veículos, apenas reduziria os espaços para estacionamento que podem ser solucionados com a criação de estacionamentos públicos ou privados.

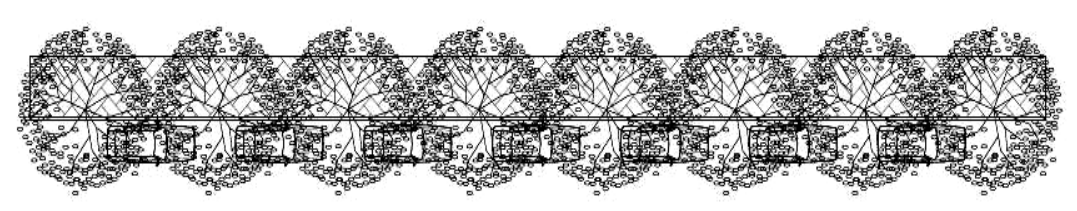

(2)

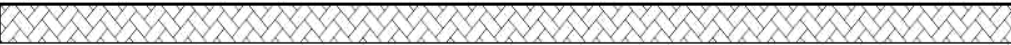

Figura 7. Croqui com o modelo de proposto para ruas com passeio público estreito.

b) Aumentar o passeio público em determinados espaços para o plantio de árvores, intercalado com espaços para estacionamento (figura 8).

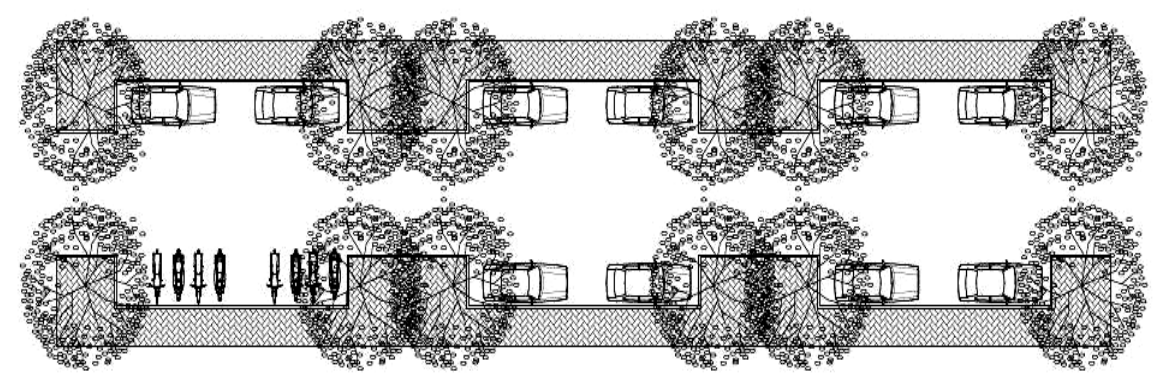

Figura 8. Croqui demonstrando a ampliação do passeio público para o plantio de árvores. 
O controle da vegetação pode ser aplicado nos demais bairros da cidade, seguindo os mesmos critérios apresentados nos dois trechos, porém destaca-se a importância de uma avaliação e análise inicial para a elaboração do diagnóstico e assim elaborar as ações.

Estas propostas podem servir de base para outros projetos que visem à melhoria da arborização urbana bem como promover um estudo mais completo sobre a eficiência desta arborização para captura do carbono atmosférico, uma vez que existem poucas informações e aplicações no Brasil.

\subsection{Recomendações para a implantação da arborização urbana}

Plantar árvores em ambientes urbanos além de ser um importante meio de capturar o carbono, aumenta a cobertura do dossel, diminui a intensidade das ilhas de calor urbano e ajuda a economizar energia utilizada para resfriamento das edificações no verão.

Para a implantação de um projeto de arborização que vise melhorar os ambientes urbanos e fazer uma captura eficiente de carbono é fundamental estabelecer parcerias com empresas, políticos, prestadores de serviços, escolas e voluntários para que juntos possam garantir o sucesso do projeto. É importante traçar um roteiro que deixe claro as estratégias que serão usadas.

Alguns critérios devem ser estabelecidos para propor um programa de arborização urbana. Destacam-se as orientações escritas por McPherson e Simpson (1999) e a forma de quantificar a captura de carbono por Nowak (1998), pois ambos possuem vários trabalhos científicos publicados em livros e artigos, com pesquisas e relatos sobre a importância da arborização em áreas urbanas, que podem servir como guia em ações implantadas no ambiente citadino. Relação de etapas que devem ser seguidas no planejamento da arborização urbana:

- Determinar uma quantidade de árvores para ser introduzida na arborização urbana anualmente, propondo metas;

- Selecionar espécies de árvores nativas que já existem na arborização urbana, pois são espécies que se adaptam bem ao clima local, solo e outras condições, tendo mais chances de sobreviver;

- Evitar ao máximo os conflitos com a rede de infraestrutura aérea e subterrânea;

- Utilizar espécies que não necessitem podas drásticas;

- Manter os usuários informados sobre a importância e o sucesso do projeto, para que haja mais participação e comprometimento na inserção e na conservação da arborização; 
- Quantificar a captura do carbono através do preenchimento de planilhas que são encontradas em programas de software, os quais armazenam dados das árvores e podem fornecer a taxa de captura;

- Optar por espécies de crescimento rápido, pois capturam mais $\mathrm{CO}_{2}$ transformando em biomassa;

- Usar espécies nativas variadas para promover uma cobertura continua do dossel bem como favorecer a fauna silvestre;

- Escolher espécies caducifólias e perenifólias procurando adaptar de acordo com o clima característico da região.

De acordo com as metas propostas e os recursos disponíveis, identificar os locais que serão arborizados para determinar o número e o tipo de árvores que serão plantadas. projeto deve ser implantado gradualmente, de preferência onde a arborização necessita manejo, por estar causando interferências na rede de infraestrutura, estar com problemas fitossanitários, causar alergias ou apenas porque existem espaços que podem ser preenchidos com o plantio de novas árvores.

A realização do inventário para analisar a arborização existente é importante, para obter um diagnóstico da atual situação da vegetação. Usando com base o diagnóstico, estabelecer quantas e quais espécies serão utilizadas, anotando os dados em uma planilha para realizar o cálculo da captura do carbono e também para monitorar o desenvolvimento das espécies.

\section{CONCLUSÃO}

Verificou-se que a vegetação urbana de Carazinho, apresenta impactos que surgiram com o desenvolvimento não planejado da cidade. As observações e o inventário da vegetação realizado in loco mostraram que a arborização existente nos logradouros analisados é, no geral, precária, mal conservada, algumas espécies são de grande porte, provocando conflitos com a rede de infraestrutura. No inventario da arborização nas 10 quadras do trecho A apenas 4 apresentam árvores no passeio publico as outra 6 não tem nenhum tipo de vegetação, pois a via de pedestre é muito estreita, fato grave numa cidade subtropical úmida com estação quente marcante que precisa da sombra das árvores para amenizar o intenso calor no verão. No treco B todas as quadras apresentam vegetação, porém não existe planejamento. 
Com base na opinião dos usuários obtidas na aplicação dos questionários, percebeuse o quanto é importante a participação dos mesmos na elaboração e aplicação do planejamento da arborização urbana, uma vez que a maioria dos entrevistados tem convicção de que a falta de planejamento na arborização urbana é a causa principal dos atuais conflitos gerados no meio ambiente local e que provocam desconforto a população.

Sobre a captura do carbono, pode-se concluir através da simulação proposta nos dois trechos de estudo, que houve um aumento significativo nessa captura, de 0,2 toneladas/ano para 1,7 toneladas/ano no trecho $\mathrm{A}$ e de 0,3 toneladas/ano para 1,1 toneladas/ano no trecho $\mathrm{B}$, isso ocorreu não somente pelo aumento do número de espécies arbóreas nativas, mas por se tratar de espécies com crescimento moderado e rápido, que absorvem mais carbono transformando-o em biomassa vegetal.

Dessa forma é importante a busca de parcerias com o poder público e/ou privado para implantação de projetos de arborização urbana bem como desenvolver programas de educação ambiental, que destaquem a importância das árvores para melhoria da ambiência urbana, fomentando o compromisso da comunidade com a arborização.

\section{REFERÊNCIAS}

COSTA, P. M. A convenção climática e o surgimento de commodities ambientais. [S.I.], Gazeta Mercantil, dez. 1997. 4 p.

COTRIJAL. Centro meteorológico da Cooperativa. Não-Me-Toque, RS, 2007.

CUNHA, G.E.;ZECHMEISTER, D.;MELO, Q.E. Elementos de arquitetura de climatização natural. Passo Fundo: UPF, 2005.

FLOSS, E.L. Fisiologia das plantas cultivadas: o estudo do que está por trás do que se vê. 3. ed. Passo Fundo: Ed. Universidade de Passo Fundo, 2006. 751p.

LOMBARDO, M.A. Vegetação e clima. In: ENCONTRO NACIONAL SOBRE

ARBORIZAÇÃO Urbana, 3., Curitiba, 1990. Anais... Curitiba: FUPEF, 1990. p.1-13.

LONGUI, Rubens Alberto. Livro das árvores: árvores e arvoretas do sul. Porto Alegre: L\&PM. 1995.

LORENZI, H. Árvores brasileiras: manual de identificação e cultivo de plantas arbóreas do Brasil. 2 ed. Nova Odessa: Plantarum. 1998 ( v 1 e 2 ), p. 
LORENZI, H. O homem deve se adaptar à árvore não ela ao homem. Folha do meio ambiente cultura viva. Brasília DF: 2001, n. 120, p. 12-17.

LORUSSO, D. C. S. Gestão de áreas verdes urbanas. In: $1^{0}$ ENCONTRO BRASILEIRO SOBRE ARBORIZAÇÃO URBANA. (1992: Vitória). Anais... Vitória, Prefeitura Municipal de Vitória, 1992. p. $181-185$.

MASCARO, L. Ambiência urbana = Urban environment. 2.ed. Porto Alegre: + 4 Editora, 2004.

McPHERSON,E.G. Benefits and costs of tree planting and care in Chicago. In:

McPherson, E.G., Nowak, D.J., Rowntree, R.A., eds. Chicago's urban forest ecosystem: results of the Chicago Urban Forest Climate Project. Gen. Tech. Rep. NE-186. Radnor, PA: U.S. Department of Agriculture, Forest Service, Northeastern Forest Experiment Station, 115-133,1994.

McPHERSON, E.G.,SIMPSON, J.R.Carbon dioxide reduction through urban forestry: guidelines for Professional and volunteer tree planters. Departamento de Agricultura dos Estados Unidos, Washington, 1999.

NOBRE, C.A. O aquecimento global e o papel do Brasil. Revista Ciências Hoje. v. 36. n. 211, dez. 2004. p.38-40.

NOWAK, D. Voluntary reporting of greenhouse gases program. U.S. Department of Energy, Washington.1998.

NOWAK,D.J;CRANE,D.E. Carbon storage e sequestration by urban trees in the USA. Environmental Pollution, London, v.116, p.381-389, July 2002.

PAIVA, H.N. Seleção de espécies para arborização urbana. Revista Ação Ambiental, Viçosa, MG. v.2, n.9, p.14-16, 1999/2000.

PAIVA, H.N.; GONÇALVES, W. Florestas urbanas: planejamento para melhoria da qualidade de vida. Viçosa: Aprenda Fácil Editora, 2002. 180 p.

SANTOS, N. R. Z.; TEIXEIRA, I. F. Arborização de Vias Públicas: Ambiente X Vegetação. Instituto Souza Cruz. Santa Cruz do Sul, RS,Ed. 2001. 135 p.

STRINGHETA, O.C.A. Arborização Urbana no Brasil. Revista Ação Ambiental.

Setembro/Outubro, 2005. Universidade Federal de Viçosa-MG. Ano VIII, n.33.p.9.

ORNSTEIN, S.W. Avaliação pós-ocupação do ambiente construído (APO). São Paulo: Studio Nobel/Edusp, 1992. 


\section{ANEXO A}

A Tabela abaixo apresenta medições do DAP (diâmetro na altura do peito) de espécies arbóreas, obtidas por David Nowak (1998) junto com o Departamento de Energia de Washington nos Estados Unidos. Além do DAP também foi observado a taxa de crescimento e idade da árvore, com o objetivo de coletar dados para o calculo aproximado da captura de carbono.

\begin{tabular}{|c|c|c|c|c|c|c|c|c|c|}
\hline \multirow{3}{*}{$\begin{array}{l}\text { Idade } \\
\text { da } \\
\text { árvore }\end{array}$} & \multicolumn{3}{|c|}{ Taxa de crescimento } & \multicolumn{6}{|c|}{ Taxa anual do seqüestro de carbono por tipo de árvore e crescimento } \\
\hline & & & & \multicolumn{3}{|c|}{ Folhosa } & \multicolumn{3}{|c|}{ Conífera } \\
\hline & Lento & Moderado & Rápido & Lento & Moderado & Rápido & Lento & Moderado & Rápido \\
\hline 0 & 0.873 & 0.873 & 0.873 & 1.3 & 1.9 & 2.7 & 0.7 & 1.0 & 1.4 \\
\hline 1 & 0.798 & 0.798 & 0.798 & 1.6 & 2.7 & 4.0 & 0.9 & 1.5 & 2.2 \\
\hline 2 & 0.736 & 0.736 & 0.736 & 2.0 & 3.5 & 5.4 & 1.1 & 2.0 & 3.1 \\
\hline 3 & 0.706 & 0.706 & 0.706 & 2.4 & 4.3 & 6.9 & 1.4 & 2.5 & 4.1 \\
\hline 4 & 0.678 & 0.678 & 0.678 & 2.8 & 5.2 & 8.5 & 1.6 & 3.1 & 5.2 \\
\hline 5 & 0.658 & 0.658 & 0.658 & 3.2 & 6.1 & 10.1 & 1.9 & 3.7 & 6.4 \\
\hline 6 & 0.639 & 0.639 & 0.644 & 3.7 & 7.1 & 11.8 & 2.2 & 4.4 & 7.6 \\
\hline 7 & 0.621 & 0.621 & 0.630 & 4.1 & 8.1 & 13.6 & 2.5 & 5.1 & 8.9 \\
\hline 8 & 0.603 & 0.603 & 0.616 & 4.6 & 9.1 & 15.5 & 2.8 & 5.8 & 10.2 \\
\hline 9 & 0.585 & 0.589 & 0.602 & 5.0 & 10.2 & 17.4 & 3.1 & 6.6 & 11.7 \\
\hline 10 & 0.568 & 0.576 & 0.589 & 5.5 & 11.2 & 19.3 & 3.5 & 7.4 & 13.2 \\
\hline 11 & 0.552 & 0.564 & 0.576 & 6.0 & 12.3 & 21.3 & 3.8 & 8.2 & 14.7 \\
\hline 12 & 0.536 & 0.551 & 0.563 & 6.5 & 3.5 & 23.3 & 4.2 & 9.1 & 16.3 \\
\hline 13 & 0.524 & 0.539 & 0.551 & 7.0 & 14.6 & 25.4 & 4.6 & 9.9 & 17.9 \\
\hline 14 & 0.512 & 0.527 & 0.539 & 7.5 & 15.8 & 27.5 & 4.9 & 10.8 & 19.6 \\
\hline 15 & 0.501 & 0.516 & 0.527 & 8.1 & 16.9 & 29.7 & 5.3 & 11.8 & 21.4 \\
\hline 16 & 0.490 & 0.504 & 0.516 & 8.6 & 18.1 & 31.9 & 5.7 & 12.7 & 23.2 \\
\hline
\end{tabular}




\begin{tabular}{|c|c|c|c|c|c|c|c|c|c|}
\hline 17 & 0.479 & 0.493 & 0.505 & 9.1 & 19.4 & 34.1 & 6.1 & 13.7 & 25.0 \\
\hline 18 & 0.469 & 0.483 & 0.495 & 9.7 & 20.6 & 36.3 & 6.6 & 14.7 & 26.9 \\
\hline 19 & 0.459 & 0.472 & 0.484 & 10.2 & 21.9 & 38.6 & 7.0 & 15.7 & 28.3 \\
\hline 20 & 0.448 & 0.462 & 0.474 & 10.8 & 23.2 & 41.0 & 7.4 & 16.7 & 30.8 \\
\hline 21 & 0.439 & 0.452 & 0.464 & 11.4 & 24.4 & 43.3 & 7.9 & 17.8 & 32.8 \\
\hline 22 & 0.429 & 0.442 & 0.454 & 12.0 & 25.8 & 45.7 & 8.3 & 18.9 & 34.9 \\
\hline 23 & 0.419 & 0.433 & 0.445 & 12.5 & 27.1 & 48.1 & 8.8 & 20.0 & 37.0 \\
\hline 24 & 0.410 & 0.424 & 0.435 & 13.1 & 28.4 & 50.6 & 9.2 & 21.1 & 39.1 \\
\hline 25 & 0.401 & 0.415 & 0.426 & 13.7 & 29.8 & 53.1 & 9.7 & 22.2 & 41.3 \\
\hline 26 & 0.392 & 0.406 & 0.417 & 14.3 & 31.2 & 55.6 & 10.2 & 23.4 & 43.5 \\
\hline 27 & 0.384 & 0.398 & 0.409 & 15.0 & 32.5 & 58.1 & 10.7 & 24.6 & 45.7 \\
\hline 28 & 0.375 & 0.389 & 0.400 & 15.6 & 33.9 & 60.7 & 11.2 & 25.8 & 48.0 \\
\hline 29 & 0.367 & 0.381 & 0.392 & 16.2 & 35.3 & 63.3 & 11.7 & 27.0 & 50.3 \\
\hline 30 & 0.359 & 0.373 & 0.383 & 16.8 & 36.8 & 65.9 & 12.2 & 28.2 & 52.7 \\
\hline 31 & 0.352 & 0.365 & 0.375 & 17.5 & 38.2 & 6.5 & 12.7 & 29.5 & 55.1 \\
\hline 32 & 0.344 & 0.358 & 0.364 & 18.1 & 39.7 & 71.2 & 13.3 & 30.7 & 57.5 \\
\hline 33 & 0.337 & 0.350 & 0.360 & 18.7 & 41.1 & 73.8 & 13.8 & 32.0 & 59.9 \\
\hline 34 & 0.330 & 0.343 & 0.349 & 19.4 & 42.6 & 76.5 & 14.3 & 33.3 & 62.4 \\
\hline 35 & 0.323 & 0.336 & 0.339 & 20.0 & 44.1 & 79.3 & 14.9 & 34.7 & 64.9 \\
\hline 36 & 0.316 & 0.329 & 0.329 & 20.7 & 45.6 & 82.0 & 15.5 & 36.0 & 67.5 \\
\hline 37 & 0.310 & 0.322 & 0.320 & 21.4 & 47.1 & 84.8 & 16.0 & 37.3 & 70.1 \\
\hline 38 & 0.303 & 0.315 & 0.310 & 22.0 & 48.6 & 87.6 & 16.6 & 38.7 & 72.7 \\
\hline 39 & 0.297 & 0.308 & 0.301 & 22.7 & 50.2 & 90.4 & 17.2 & 40.1 & 75.3 \\
\hline 40 & 0.291 & 0.303 & 0.293 & 23.4 & 51.7 & 93.2 & 17.7 & 41.5 & 78.0 \\
\hline 41 & 0.285 & 0.296 & 0.284 & 24.1 & 53.3 & 96.1 & 18.3 & 42.9 & 80.7 \\
\hline 42 & 0.279 & 0.289 & 0.276 & 24.8 & 54.8 & 99.0 & 18.9 & 44.3 & 83.4 \\
\hline 43 & 0.273 & 0.283 & 0.268 & 25.4 & 56.4 & 101.9 & 19.5 & 45.8 & 86.2 \\
\hline 44 & 0.267 & 0.277 & 0.260 & 26.1 & 58.0 & 104.8 & 20.1 & 47.2 & 89.0 \\
\hline 45 & 0.261 & 0.269 & 0.253 & 26.8 & 59.6 & 107.7 & 20.7 & 48.7 & 91.8 \\
\hline 46 & 0.256 & 0.261 & 0.245 & 27.6 & 61.2 & 110.7 & 21.3 & 50.2 & 94.7 \\
\hline 47 & 0.251 & 0.254 & 0.238 & 28.3 & 62.8 & 113.6 & 22.0 & 51.7 & 97.5 \\
\hline 48 & 0.245 & 0.247 & 0.231 & 29.0 & 64.5 & 116.6 & 22.6 & 53.2 & 100.4 \\
\hline 49 & 0.240 & 0.239 & 0.225 & 29.7 & 66.1 & 119.6 & 23.2 & 54.8 & 103.4 \\
\hline 50 & 0.235 & 0.232 & 0.218 & 30.4 & 67.8 & 122.7 & 23.9 & 56.3 & 106.3 \\
\hline 51 & 0.230 & 0.226 & 0.212 & 31.1 & 69.4 & 125.7 & 24.5 & 57.9 & 109.3 \\
\hline 52 & 0.225 & 0.219 & 0.206 & 31.9 & 71.1 & 128.8 & 25.2 & 59.4 & 112.3 \\
\hline 53 & 0.221 & 0.213 & 0.199 & 32.6 & 72.8 & 131.8 & 25.8 & 61.0 & 115.4 \\
\hline 54 & 0.216 & 0.207 & 0.193 & 33.4 & 74.5 & 134.9 & 26.5 & 62.6 & 118.4 \\
\hline 55 & 0.211 & 0.201 & 0.188 & 34.1 & 76.2 & 138.0 & 27.2 & 64.2 & 121.5 \\
\hline
\end{tabular}

Fonte: U.S Department of Energy, (NOWAK,1998)

\section{ANEXO B}

Espécies arbóreas nativas que melhor se adaptam ao clima e solo em Carazinho RS, para a seleção dessas espécies foi adotado os critérios estabelecidos no trabalho de pesquisa, dando preferência para as árvores de crescimento moderado e rápido, uma vez que estas absorvem uma quantidade maior de $\mathrm{CO}_{2}$ da atmosfera, transformando em biomassa vegetal.

\begin{tabular}{|c|c|c|c|c|c|}
\hline Nome comum & Nome cientifico & Família & Porte & $\begin{array}{c}\text { Persistência } \\
\text { foliar }\end{array}$ & $\begin{array}{c}\text { Tempo de } \\
\text { crescimento }\end{array}$ \\
\hline $\begin{array}{c}\text { Aroeira- } \\
\text { periquita }\end{array}$ & Schinus molle & Anacardiaceae & Pequeno & Perene & Rápido \\
\hline Cambará & Gochnatia polymorpha & Asteraceae & Médio & Decídua & Rápido \\
\hline $\begin{array}{c}\text { Jacarandá } \\
\text { mimoso }\end{array}$ & Jacarandá mimosaefolia & Bignoniaceae & Grande & Decídua & Rápido \\
\hline Chal-Chal & Allphyllus edulis & Sapindaceae & Pequena & Decídua & Rápido \\
\hline Bolão-de-ouro & Senna macranthera & Caesalpinoideae & Médio & Decídua & Rápido \\
\hline Jerivá & Syagrus romanzoffiana & Arecaceae & Grande & Perene & Moderado \\
\hline Manacá-da- & Tibouchina mutabilis & Melastomataceae & Pequeno & Perene & Moderado \\
\hline
\end{tabular}




\begin{tabular}{|c|c|c|c|c|c|}
\hline serra & & & & & Moderado \\
\hline Sibipiruna & Caesalpinia peltophoroides & Leguminosae & Grande & Decídua & Moderado \\
\hline $\begin{array}{c}\text { Falso } \\
\text { barbatimão }\end{array}$ & Cássia leptophylla & Leguminosae & Médio & Perene & Rápido \\
\hline Ipê amarelo & Tabebuia alba & Bignoneaceae & Médio & Decídua & Moderado \\
\hline Ipê roxo & Tabebuia avellanedae & Bignoneaceae & Grande & Decídua & Rápido \\
\hline Pata-de-vaca & Bauhinia forficata & Leguminosae & Pequeno & Decídua & Rápido \\
\hline Ingá-feijão & Ingá marginata & Mimosoideae & Médio & Perene & Rápido \\
\hline Canela & Nectandra sp & Lauraceae & Grande & Perene & nando
\end{tabular}

Fonte: LORENZI ( 1998 e 2001), LONGUI (1995) 